\title{
openheart Modifiable risk factors predict incident atrial fibrillation and heart failure
}

\author{
Jorge A Wong (1) , ${ }^{1,2}$ David Conen, ${ }^{1,2}$ Jeff S Healey, ${ }^{1,2}$ Linda S B Johnson ${ }^{1,3}$
}

\begin{abstract}
- Additional material is published online only. To view please visit the journal online (http://dx.doi.org/10.1136/ openhrt-2019-001092).
\end{abstract}

To cite: Wong JA, Conen D, Healey JS, et al. Modifiable risk factors predict incident atrial fibrillation and heart failure. Open Heart 2020;7:e001092. doi:10.1136/

openhrt-2019-001092

Received 19 May 2019 Revised 23 January 2020 Accepted 12 February 2020

Check for updates

\section{(c) Author(s) (or their} employer(s)) 2020. Re-use permitted under CC BY-NC. No commercial re-use. See rights and permissions. Published by BMJ.

${ }^{1}$ Population Health Research Institute, Hamilton, Ontario, Canada

${ }^{2}$ Department of Medicine, McMaster University, Hamilton, Ontario, Canada

${ }^{3}$ Department of Clinical Sciences, Lund University, Lund, Sweden

Correspondence to Dr Jorge A Wong; wongjas@ mcmaster.ca

\section{ABSTRACT}

Objective Heart failure (HF) frequently complicates atrial fibrillation (AF) and significantly increases mortality risk. Limited data exist on the modifiable risk factors associated with development of $\mathrm{HF}$ in AF patients.

Methods We examined two large, prospective, population-based cohorts without prior AF or $\mathrm{HF}$ at baseline: Malmö Preventive Project (MPP, $n=32625$ ) and Malmö Diet and Cancer Study (MDCS, $n=27695$ ). Using Lunn-McNeil competing risks, multivariable Cox models were constructed to determine hazard ratios (HR) and $95 \%$ confidence intervals $(\mathrm{Cl})$ of risk factors for incident $\mathrm{HF}$ with $\mathrm{AF}$, and $\mathrm{AF}$ alone.

Results Mean follow-up in MPP and MDCS was 27.6 \pm 8.4 and $17.7 \pm 5.3$ years. In MPP, body mass index (HR $1.11,95 \% \mathrm{Cl} 1.09$ to 1.13 vs HR $1.05,95 \% \mathrm{Cl} 1.04$ to 1.06 per $\mathrm{kg} / \mathrm{m}^{2}$ ), systolic blood pressure (HR $1.20,95 \% \mathrm{Cl}$ 1.24 to 1.26 vs HR $1.08,95 \% \mathrm{Cl} 1.06$ to 1.10 per $10 \mathrm{~mm}$ $\mathrm{Hg}$ ) and current cigarette smoking (HR 1.73, 95\% Cl 1.54 to 1.95 vs HR $1.23,95 \% \mathrm{Cl} 1.15$ to 1.32 ) had stronger associations with incident AF with $\mathrm{HF}$ compared with $\mathrm{AF}$ alone (all $p$ for difference $<0.0001$ ). Similar results were observed in MDCS (all $p$ for difference $<0.009$ ). These three risk factors and diabetes accounted for $51.8 \%$ and $54.1 \%$ of the population attributable risk (PAR) for AF with HF in MPP and MDCS, respectively, compared with $20.1 \%$ and $27.0 \%$ for AF alone.

Conclusions Obesity, hypertension and active smoking preferentially associated with $\mathrm{AF}$ with $\mathrm{HF}$, compared with AF alone, and accounted for $>50 \%$ of the PAR. Randomised trials are needed to assess whether risk factor modification can reduce the incidence of AF with $\mathrm{HF}$ and reduce mortality.

\section{INTRODUCTION}

Heart failure (HF) represents one of the cardiovascular epidemics of the $21^{\text {st }}$ century and is a global public health problem. ${ }^{1}$ The prevalence of HF is increasing and the condition is associated with increased morbidity, mortality and high costs of care. ${ }^{23}$ Despite significant improvements in the care of HF patients in the last two decades, their outcomes remain poor with mortality rates of $50 \%$ at 5 years, rivalling many cancers. ${ }^{2}$ Given the significant and persistent poor outcomes associated with HF, increased efforts at identifying and increasing our understanding of modifiable risk factors predisposing to $\mathrm{HF}$

\section{Key questions}

What is already known about this subject?

- Heart failure (HF) is a common complication in patients with atrial fibrillation (AF), and when both conditions occur together, there is a significant increase in the risk of mortality. Limited data exist on the modifiable risk factors associated with the development of HF in patients with AF.

What does this study add?

- Hypertension, obesity and current smoking were more strongly associated with the development of $\mathrm{AF}$ and $\mathrm{HF}$ compared with $\mathrm{AF}$ alone. The three risk factors and diabetes accounted for $>50 \%$ of the population attributable risk of AF and HF. The present study is the largest to date examining the modifiable risk factors associated with the development of the combination of AF and HF.

How might this impact on clinical practice?

- Clinical trials are needed to assess whether risk factor modification can reduce the risk of HF in patients with $\mathrm{AF}$, and subsequently reduce mortality.

require emphasis, as such knowledge may lead to development of novel preventive and management strategies.

Atrial fibrillation (AF) represents the most common arrhythmia, is highly prevalent in patients with $\mathrm{HF}$ and is also a major cause of morbidity and mortality. ${ }^{4-7} \mathrm{AF}$ and $\mathrm{HF}$ are intimately related in terms of pathophysiology; both conditions predispose to each other, and have many shared risk factors. ${ }^{6}$ When AF and HF occur together, the risk of mortality increases two to three fold, irrespective of their temporal occurrence. ${ }^{568}$ Furthermore, therapies known to improve adverse outcomes in HF patients do not appear to carry over to patients with both $\mathrm{HF}$ and AF. ${ }^{9}$ Given the strong link between $\mathrm{HF}$ and AF, and the poor outcomes associated with the development of both conditions, focus on preventing the occurrence of the combination of both $\mathrm{AF}$ and $\mathrm{HF}$ may thus present an important strategy to improve clinical outcomes. 
In order to identify the modifiable risk factors predisposing to both $\mathrm{AF}$ and $\mathrm{HF}$ and their prognostic significance, we analysed data from the Malmö Preventive Project (MPP) ${ }^{10}$ and Malmö Diet and Cancer Study (MDCS), ${ }^{11}$ two large population-based, longitudinal prospective cohort studies. We hypothesised that a considerable proportion of the risk of developing both $\mathrm{AF}$ and $\mathrm{HF}$ can be explained by modifiable risk factors, and that these factors may represent important preventative targets.

\section{METHODS}

\section{Study populations}

The MPP and MDCS cohorts have been previously described. ${ }^{10} 11$ MPP is composed of 33346 individuals (67\% men, mean age 45.7 years) from the city of Malmö, Sweden, who participated in a screening programme to identify individuals at high risk for cardiovascular events. Recruitment was through invitation of full prespecified age-cohorts and attendance rate was $>70 \%$. Men were screened during 1974 to 1982 and women between 1982 and 1992. ${ }^{10}$ For the purposes of this analysis, we excluded subjects with prevalent AF $(n=44)$, HF $(n=8)$ or missing data for systolic blood pressure (SBP, $n=36)$, height $(n=4)$, weight $(n=2)$ or smoking status $(n=627)$. Final study population consisted of 22382 men and 10243 women. MDCS consists of 28098 individuals from Malmö (39\% men, mean age 58.2 years) who participated in baseline examination during 1991 to 1996 . Men born between 1923 and 1945 and women born between 1923 and 1950 were invited to participate. ${ }^{11}$ The attendance rate was around $\sim 40 \%$. For this analysis, we excluded subjects with prevalent AF $(n=268)$, prevalent HF $(n=52)$ or missing data for SBP $(n=42)$, height $(n=28)$, weight $(n=1)$ or smoking status $(n=12)$. Final study population consisted of 10832 men and 16863 women.

\section{Data collection}

Height and weight were measured standing in light indoor clothes using a fixed stadiometer and a balance beam scale. Body mass index (BMI) was calculated as $\mathrm{kg} /$ $\mathrm{m}^{2}$. Blood pressure was measured twice after $10 \mathrm{~min}$ of supine rest. Blood samples were drawn after overnight rest and analysed using standard laboratory procedures at the Department of Clinical Chemistry at Malmö University Hospital. Current smoking was defined as selfreported smoking at the time of screening. Sedentary lifestyle was defined as a positive answer to the question 'Are you mostly sedentary in your spare time?' in MPP and as the lowest sex-specific quartile of a previously described modification of the Minnesota Leisure Time Physical Activity Questionnaire in the MDCS. ${ }^{12}$ In MPP, alcohol use was defined as risk use in subjects with two or more positive answers to a modification of the Michigan Alcohol Screening test (Mm-Mast) ${ }^{13}$ and in MDCS, alcohol use was defined in terms of $\mathrm{g}$ /day consumption derived from a self-reported dietary questionnaire. Low socioeconomic index was defined as Statistics Sweden group 11 to 36 in the MPP and as 9 years of schooling or less in the MDCS.

\section{Endpoint retrieval and national registries}

The endpoints of this analysis were incident $\mathrm{AF}$ and $\mathrm{HF}$, diagnosed in a hospital setting and retrieved from the Swedish Registers for inpatients and outpatients, administered by the Swedish National Board of Health and Welfare. All Swedish residents are included in these registers and therefore there was no missing data at the time of registry linkage. The inpatient register has been in use in the south of Sweden during the entire follow-up and became nation-wide in 1987. The outpatient register became operational in 2000. Incident $\mathrm{AF}$ was defined as diagnosis codes 427.92 (InternationalClassification of Diseases (ICD)-8), 427D (ICD-9) and I48 (ICD-10). The $\mathrm{AF}$ diagnosis has recently been validated and found to be of high quality (95\% accurate).${ }^{14} \mathrm{AF}$ and atrial flutter have not been distinguished due to similarities of these diagnoses. HF was defined as a primary diagnosis with codes 428 (ICD-9) or I.11 (ICD-9). The HF register diagnosis has also been validated and is $>95 \%$ accurate.$^{15}$ Patients who had AF without HF were defined as those individuals with incident $\mathrm{AF}$ during follow-up who did not experience an HF diagnosis. Patients who had AF with HF were defined as individuals with incident AF during follow-up and whose AF diagnosis was either preceded or followed by an HF diagnosis.

\section{Statistical analyses}

Analyses were performed using Stata for Macintosh (V.15.1. Stata Corporation, College Station, Texas). In order to evaluate mortality across categories of AF and $\mathrm{HF}$, we calculated incidence rates for mortality across four groups: $\mathrm{AF}$ without prevalent $\mathrm{HF}$, AF with prevalent $\mathrm{HF}, \mathrm{HF}$ without prevalent $\mathrm{AF}$ and $\mathrm{HF}$ with prevalent AF. Sex-adjusted and age-adjusted incidence rates were calculated from the time of first diagnosis of AF or HF, whichever occurred first, using 10-year age strata with weights derived from the total number of corresponding $\mathrm{AF}$ or HF cases. HRs were calculated using a competing risks approach in stratified Cox regression described by Lunn and $\mathrm{McNeil}^{16}$ as previously described, which allow for separate estimations of the relative hazard between covariates and each outcome (AF without $\mathrm{HF}$ vs $\mathrm{AF}$ with HF) under a proportional hazards assumption. ${ }^{17}$ Briefly, the method involves duplication of the data set so that each subject occurs in two strata. The failures were separated by strata, with $\mathrm{AF}$ without $\mathrm{HF}$ occurring only in one strata and AF with HF only in the other, and the covariates duplicated resulting in separate but identical variables in each stratum that are assigned the value of 0 in the other stratum. A stratified Cox regression analysis was performed, by failure stratum, which produces cause specific HRs for each failure. After this, for each covariate, another stratified Cox regression was performed, with a single covariate included as an unduplicated variable. 
This forces the model to give the same effect estimate for the unduplicated variable in both strata. This model was then compared with the model where effect sizes were allowed to be different over strata using the likelihood ratio test. $\mathrm{P}$ values for difference in effect sizes are thus derived from the likelihood ratio test. The same multivariable model, including age, sex, height, BMI, systolic blood pressure, current smoking, prevalent coronary events and prevalent diabetes, was used in both cohorts. These variables were prespecified, with the intention to include the most important modifiable risk factors for $\mathrm{AF}$ available in both cohorts. ${ }^{11}$ Continuous variables were assessed for normality and non-normal variables (alcohol use in the MDCS) were log transformed before inclusion in the model, after adding the small constant 1. Patients were censored at the first diagnosis of $\mathrm{AF}$ for the outcome of $\mathrm{AF}$ without $\mathrm{HF}$, at the first diagnosis of either $\mathrm{AF}$ or $\mathrm{HF}$ for the outcome of AF with HF, and all other subjects were censored at death, emigration from Sweden or end of follow-up (31 December 2013 in the MPP and 31 December 2014 in the MDCS). To assess the competing risk of death on results, we conducted a competing risks regression as described by Fine and Gray, with each endpoint modelled separately. In order to assess whether the risk factor profile for the combination of $\mathrm{AF}$ and HF differed by whether AF or HF occurred first, we also conducted a sensitivity analysis excluding cases of AF with $\mathrm{HF}$ when the HF diagnosis occurred before the AF event. Finally, as there was some missing data for alcohol use and sedentary lifestyle, these covariates were therefore also examined in sensitivity analyses.

Population attributable risks (PAR) for modifiable risk factors were calculated using failure-specific endpoints, with the Stata plug-in punafcc, and under the assumption of a causal relationship. ${ }^{18}$ The model included age, sex, height, current smoking, systolic blood pressure $>140 \mathrm{~mm}$ $\mathrm{Hg}, \mathrm{BMI}>25 \mathrm{~kg} / \mathrm{m}^{2}$, prevalent diabetes and known prevalent coronary events. For the PAR calculations, the modifiable predictors of interest were dichotomised to be either present or absent. The PAR's derived from this model represent a comparison between the observed data and hypothetical scenarios without either smoking, systolic blood pressure $>140 \mathrm{~mm} \mathrm{Hg}$, BMI $>25 \mathrm{~kg} / \mathrm{m}^{2}$, prevalent diabetes or known prevalent coronary events, with all other factors remaining equal.

\section{RESULTS}

Baseline characteristics are reported in table 1. Briefly, the MPP cohort had a younger mean age at baseline screening and a greater proportion of male participants than MDCS. Mean follow-up (SD) was 27.6 (8.4) years in MPP and 17.7 (5.3) years in MDCS. There were 3277 incident cases of AF without HF (cumulative incidence $10.0 \%$ ) in MPP and 3167 cases (cumulative incidence $11.4 \%$ ) in MDCS. There were 1153 cases of AF with HF in MPP (cumulative incidence $3.5 \%$ ) and 890 cases (cumulative incidence $3.2 \%$ ) in MDCS. Among those with AF and HF, the diagnosis of AF preceded HF diagnosis in 622 cases $(53.9 \%)$ in MPP and 537 cases in MDCS $(60.3 \%)$, and was concurrent in 213 cases (18.5\%) in MPP and 146 cases in MDCS (16.4\%). Age and gender adjusted incidence rates for mortality are depicted in table 2 . AF subjects with prevalent HF had a higher adjusted incidence rate for mortality compared with patients with $\mathrm{AF}$ or HF alone.

Results from the multivariable stratified Cox regression model with $p$ values for difference in effect estimates between the $\mathrm{AF}$ with $\mathrm{HF}$ and $\mathrm{AF}$ without $\mathrm{HF}$ groups are reported in table 3 . In both cohorts elevated BMI, elevated systolic blood pressure and current smoking independently predicted both $\mathrm{AF}$ without $\mathrm{HF}$, and $\mathrm{AF}$ with HF. However, the effect estimates for these variables were significantly and substantially higher for AF with $\mathrm{HF}$, compared with AF alone. BMI $>25 \mathrm{~kg} / \mathrm{m}^{2}$, systolic blood pressure $>140 \mathrm{~mm} \mathrm{Hg}$ and current cigarette smoking were associated with a greater risk of developing $\mathrm{AF}$ with HF in both MPP (HR 1.80, 95\% CI 1.59 to 2.03; HR $1.71,95 \%$ CI 1.51 to 1.95 ; HR $1.73,95 \%$ CI 1.54 to 1.95 , respectively) and MDCS cohorts (HR 1.63, 95\% CI 1.41 to 1.89 ; HR $1.48,95 \%$ CI 1.27 to 1.73 ; HR $1.67,95 \%$ CI 1.43 to 1.94 , respectively). Prevalent diabetes was associated with an increased risk of AF with HF in MDCS (HR $1.78,95 \%$ CI 1.43 to 2.22 ), a finding that was borderline significant in MPP (HR 1.29, 95\% CI 0.99 to 1.66). Prevalent coronary events were associated with a greater risk of AF with $\mathrm{HF}$ in MDCS, but was similarly associated with AF without HF in MPP. In sensitivity analysis, we observed similar results when study participants who developed $\mathrm{HF}$ prior to $\mathrm{AF}$ were excluded from the analysis (online supplementary table 1 ).

A competing risks analysis was performed in order to assess the effect of death as a competing risk (table 4) and similar results were observed. We additionally tested whether the inclusion of alcohol use, sedentary lifestyle and low socioeconomic index influenced the results, by including these variables in the Lunn-McNeil model (online supplementary table 2), and found that inclusion of these variables did not influence the results substantially.

The population attributable risk of $\mathrm{AF}$ with $\mathrm{HF}$ due to obesity, systolic hypertension and current cigarette smoking can be seen in table 5 . The combination of BMI $\geq 25 \mathrm{~kg} / \mathrm{m}^{2}$, systolic blood pressure $\geq 140 \mathrm{~mm} \mathrm{Hg}$ and active cigarette smoking accounted for $51.3 \%$ (95\% CI 47.4 to 54.9 ) and 52.9 (95\% CI 46.3 to 58.7 ) of the population attributable risk of AF with HF in the MPP and MDCS cohorts, respectively. Similar results were obtained when results were stratified by sex (table 5 ).

\section{DISCUSSION}

In this prospective analysis of the modifiable risk factors associated with development of the combination of $\mathrm{AF}$ and $\mathrm{HF}$, in two large, population-based, longitudinal cohorts free of $\mathrm{AF}$ and $\mathrm{HF}$ at baseline, we have identified several 
Table 1 Baseline characteristics by incident event status

\begin{tabular}{|c|c|c|c|c|c|c|}
\hline & MPP & & & MDCS & & \\
\hline & $\begin{array}{l}\text { Full population } \\
(n=32625)\end{array}$ & $\begin{array}{l}\text { AF without HF } \\
(n=3277)\end{array}$ & $\begin{array}{l}\text { AF with } \mathrm{HF}^{*} \\
(\mathrm{n}=1153)\end{array}$ & $\begin{array}{l}\text { Full population } \\
(\mathrm{n}=27695)\end{array}$ & $\begin{array}{l}\text { AF without HF } \\
(n=3167)\end{array}$ & $\begin{array}{l}\text { AF with } \mathrm{HF}^{*} \\
(\mathrm{n}=890)\end{array}$ \\
\hline Age, years & $45.5(7.4)$ & $47.4(6.3)$ & $48.6(5.9)$ & $58.1(7.6)$ & $61.5(7.1)$ & $63.6(6.3)$ \\
\hline Follow-up time, years & $29.8(23.5-33.8)$ & $26.2(20.7-30.6)$ & 23.4 (17.0-28.4) & $19.8(18.0-21.4)$ & 19.9 (18.0-21.6) & $14.8(10.1-18.2)$ \\
\hline $\begin{array}{l}\text { Time to AF diagnosis, } \\
\text { years }\end{array}$ & $25.8(20.2-30.2)$ & $26.2(20.7-30.6)$ & 24.5 (18.7-29.3) & $14.1(9.7-14.5)$ & $14.3(10.0-17.8)$ & $12.8(8.4-16.6)$ \\
\hline $\begin{array}{l}\text { Age at AF diagnosis, } \\
\text { years }\end{array}$ & 73.4 (66.8-78.5) & $73.5(66.8-78.6)$ & $73.2(66.8-78.3)$ & 75.8 (69.9-81.2) & 75.5 (69.5-81.1) & 76.4 (71.0-81.3) \\
\hline $\begin{array}{l}\text { Survival after AF, } \\
\text { years }\end{array}$ & $4.2(1.4-8.6)$ & $4.2(1.3-8.6)$ & $4.6(1.5-8.6)$ & $4.2(1.6-8.1)$ & $4.1(1.5-8.1)$ & $4.6(1.7-8.3)$ \\
\hline Female sex, $\%$ & 31.4 & 28.0 & 23.2 & 60.9 & 50.5 & 44.2 \\
\hline Height, cm & $173(9)$ & $175(9)$ & $174(8)$ & $169(9)$ & $170(9)$ & $171(9)$ \\
\hline $\mathrm{BMI}, \mathrm{kg} / \mathrm{m}^{2}$ & $24.6(3.6)$ & $25.1(3.8)$ & $26.3(4.2)$ & $25.7(4.0)$ & $26.6(4.1)$ & $27.5(4.4)$ \\
\hline $\mathrm{BMI}>25 \mathrm{~kg} / \mathrm{m}^{2}, \%$ & 39.5 & 46.0 & 58.4 & 52.7 & 61.6 & 69.3 \\
\hline $\mathrm{SBP}, \mathrm{mm} \mathrm{Hg}$ & $126(16)$ & $129(16)$ & $133(17)$ & $141(20)$ & $147(20)$ & $152(20)$ \\
\hline $\mathrm{SBP}>140 \mathrm{~mm} \mathrm{Hg}, \%$ & 12.5 & 15.5 & 24.8 & 43.0 & 55.5 & 66.6 \\
\hline FBG, mmol/L† & $4.9(0.7)$ & $4.9(0.7)$ & $4.9(0.8)$ & $4.9(0.7)$ & $5.0(0.8)$ & $5.1(0.9)$ \\
\hline $\begin{array}{l}\text { Current smoking } \\
\text { status, } \%\end{array}$ & 45.4 & 42.4 & 49.0 & 28.3 & 22.8 & 27.5 \\
\hline Sedentary lifestyle, \% & 55.2 & 52.2 & 53.7 & 25.0 & 24.3 & 27.6 \\
\hline Alcohol risk use, $\%$ & 27.0 & 26.8 & 29.6 & & & \\
\hline Alcohol, g/day $\dagger$ & & & & $7.2(13.7)$ & $7.6(14.2)$ & $7.5(14.2)$ \\
\hline Prevalent diabetes & 3.4 & 2.8 & 5.6 & 4.3 & 4.5 & 10.2 \\
\hline $\begin{array}{l}\text { Prevalent coronary } \\
\text { event }\end{array}$ & 0.4 & 0.5 & 1.2 & 1.9 & 2.8 & 8.0 \\
\hline
\end{tabular}

Values are mean (SD) or median (IQR), unless stated otherwise. Follow-up time in MPP and MDCS was 27.6 (8.4) and 17.7 (5.3) years, respectively.

*Includes subjects with HF before AF.

†Presented as median and IQR.

.AF, atrial fibrillation; BMI, body mass index; FBG, fasting blood glucose; HF, heart failure; MDCS, Malmö Diet and Cancer Study; MPP, Malmö

Preventive Project; SBP, systolic blood pressure.

important findings. First, among patients who developed both $\mathrm{AF}$ and $\mathrm{HF}, \mathrm{AF}$ appeared to more frequently precede the occurrence of HF. Second, elevated BMI, systolic blood pressure $\geq 140 \mathrm{~mm} \mathrm{Hg}$ and active smoking were stronger predictors of $\mathrm{AF}$ with $\mathrm{HF}$, than $\mathrm{AF}$ alone; a finding which persisted after sensitivity analysis. Third, these modifiable

Table 2 Incidence rates $(95 \% \mathrm{Cl})$ for mortality, per 1000 person-years

\begin{tabular}{|c|c|c|c|c|}
\hline & HF without prevalent $\mathrm{AF}^{*}$ & HF with prevalent AF† & AF without prevalent HF¥ & AF with prevalent HF§ \\
\hline \multicolumn{5}{|l|}{ MPP } \\
\hline Unadjusted & $160(150-170)$ & $188(170-207)$ & $68(65-71)$ & $202(176-231)$ \\
\hline Adjustedף & $209(192-226)$ & $200(178-221)$ & $95(90-100)$ & $214(183-246)$ \\
\hline \multicolumn{5}{|l|}{ MDCS } \\
\hline Unadjusted & $164(150-178)$ & $204(183-228)$ & $70(67-74)$ & 235 (199-278) \\
\hline Adjusted & $220(197-242)$ & $230(200-260)$ & $91(85-96)$ & $423(56-790)$ \\
\hline
\end{tabular}

*Based on 1324 individuals and 942 deaths in the MPP and 814 individuals and 541 deaths in the MDCS.

†Based on 622 individuals, and 384 deaths in the MPP and 537 individuals and 318 deaths in the MDCS.

¥Based on 3899 individuals and 1668 deaths in the MPP and 3704 individuals and 1449 deaths in the MDCS.

§Based on 318 individuals and 202 deaths in the MPP and 207 individuals and 135 deaths in the MDCS.

IAdjusted for sex and age at the time of diagnosis of AF and HF respectively, in 10-year age bands.

AF, atrial fibrillation; HF, heart failure; MDCS, Malmö Diet and Cancer Study; MPP, Malmö Preventive Project. 


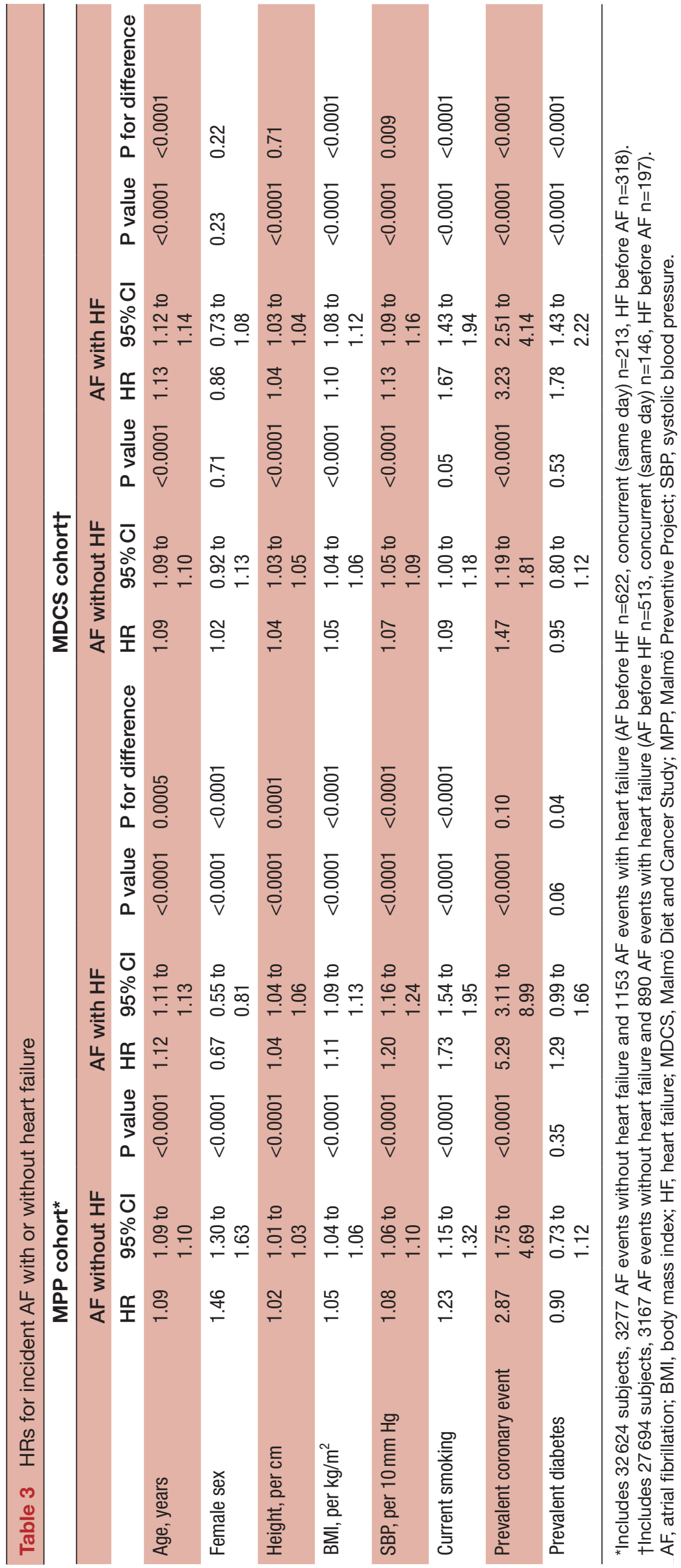


Table 4 Competing risks models for incident AF with and without heart failure

\begin{tabular}{|c|c|c|c|c|c|c|c|c|c|c|c|c|}
\hline & \multicolumn{6}{|c|}{ MPP cohort* } & \multicolumn{6}{|c|}{ MDCS cohort } \\
\hline & \multicolumn{3}{|c|}{ AF without HF } & \multicolumn{3}{|c|}{ AF with HF } & \multicolumn{3}{|c|}{ AF without HF } & \multicolumn{3}{|c|}{ AF with HF } \\
\hline & HR & $95 \% \mathrm{Cl}$ & $P$ value & HR & $95 \% \mathrm{Cl}$ & $P$ value & HR & $95 \% \mathrm{Cl}$ & $P$ value & HR & $95 \% \mathrm{Cl}$ & $P$ value \\
\hline Female, sex & 0.86 & $\begin{array}{l}0.77 \text { to } \\
0.96\end{array}$ & 0.009 & 0.42 & $\begin{array}{l}0.35 \text { to } \\
0.52\end{array}$ & $<0.0001$ & 0.99 & $\begin{array}{l}0.89 \text { to } \\
1.10\end{array}$ & 0.83 & 0.86 & $\begin{array}{l}0.70 \text { to } \\
1.06\end{array}$ & 0.16 \\
\hline BMI, per $\mathrm{kg} / \mathrm{m}^{2}$ & 1.05 & $\begin{array}{l}1.03 \text { to } \\
1.06\end{array}$ & $<0.0001$ & 1.11 & $\begin{array}{l}1.09 \text { to } \\
1.12\end{array}$ & $<0.0001$ & 1.05 & $\begin{array}{l}1.04 \text { to } \\
1.06\end{array}$ & $<0.0001$ & 1.10 & $\begin{array}{l}1.08 \text { to } \\
1.11\end{array}$ & $<0.0001$ \\
\hline SBP, per $10 \mathrm{~mm} \mathrm{Hg}$ & 1.08 & $\begin{array}{l}1.06 \text { to } \\
1.11\end{array}$ & $<0.0001$ & 1.20 & $\begin{array}{l}1.16 \text { to } \\
1.24\end{array}$ & $<0.0001$ & 1.06 & $\begin{array}{l}1.04 \text { to } \\
1.08\end{array}$ & $<0.0001$ & 1.12 & $\begin{array}{l}1.08 \text { to } \\
1.16\end{array}$ & $<0.0001$ \\
\hline Prevalent diabetes & 0.86 & $\begin{array}{l}0.70 \text { to } \\
1.06\end{array}$ & 0.16 & 1.28 & $\begin{array}{l}0.98 \text { to } \\
1.66\end{array}$ & 0.07 & 0.95 & $\begin{array}{l}0.80 \text { to } \\
1.12\end{array}$ & 0.53 & 1.82 & $\begin{array}{l}1.43 \text { to } \\
2.27\end{array}$ & $<0.0001$ \\
\hline
\end{tabular}

*Includes 32624 subjects, 3277 AF events without heart failure and 1153 AF events with heart failure (AF before HF $n=622$, concurrent (same day) $n=213$, HF before $A F n=318$ ).

†Includes 27694 subjects, 3167 AF events without heart failure and 890 AF events with heart failure (AF before HF $n=513$, concurrent (same day) $n=146$, HF before AF $n=197$.

AF, atrial fibrillation; BMI, body mass index; HF, heart failure; MDCS, Malmö Diet and Cancer Study; MPP, Malmö Preventive Project; SBP, systolic blood pressure.

risk factors accounted for over $50 \%$ of the PAR for incident AF with HF. Similar PAR's were observed between men and women when we stratified our results by sex. Our findings suggest that risk factor modification may have significant implications in the reduction of both $\mathrm{AF}$ and HF.

In the present study, we report the largest analysis to date examining the modifiable risk factors associated with developing the combination of AF and HF. Studies of incident HF among patients with AF have focussed primarily on risk prediction and have thus examined the combination of both modifiable and non-modifiable risk factors. ${ }^{19-21}$ Only one prior study has exclusively evaluated the modifiable risk factors associated with subsequent $\mathrm{HF}$ development in AF patients. ${ }^{22}$ In a subcohort of 1495 female healthcare professionals with AF within the Women's Health Study, Chatterjee et al found that systolic blood pressure $>120 \mathrm{~mm} \mathrm{Hg}, \mathrm{BMI}>30 \mathrm{~kg} / \mathrm{m}^{2}$, current tobacco smoking and diabetes were independent predictors of the development of HF after AF. In the present analysis, which examined a population-based cohort and included $>5$ fold the number of AF cases than the Women's Health Study, we hypothesised that it did not matter whether AF or HF occurred first, but that the occurrence of both conditions would be associated with worse outcomes. In this context, we similarly found that elevated blood pressure, elevated BMI and active cigarette smoking were preferentially associated with the subsequent development of the combination of $\mathrm{AF}$ and HF. Diabetes was a significant risk factor for $\mathrm{AF}$ with $\mathrm{HF}$ in the MDCS cohort, but borderline significant in the MPP cohort; a finding likely attributed to the low prevalence of diabetes in MPP at baseline. Our findings remained significant when we excluded the subset of patients who developed HF prior to AF. These baseline risk factors in a population initially free of both $\mathrm{AF}$ and $\mathrm{HF}$ could predict the subsequent development of the combination of $\mathrm{AF}$ with $\mathrm{HF}$ many years later speak to their importance and robustness. Overall, our results are in agreement with data reported from the Women's Health Study and extend these findings to their male counterparts. ${ }^{22}$

Obesity appeared to account for the largest proportion of the PAR for incident AF with HF. This is consistent with literature supporting an important role for obesity in the development of both AF and HF, individually. In the Women's Health Study, short-term elevations in BMI in the obesity range accounted for $18.3 \%$ of incident $\mathrm{AF}^{23}$ In addition, in the Framingham Heart Study, the population attributable risk for $\mathrm{HF}$ due to obesity was estimated to be $10.9 \%$ for men and $13.9 \%$ for women. ${ }^{24}$ In the present study, a BMI $>25 \mathrm{~kg} / \mathrm{m}^{2}$ accounted for $11.1 \%$ to $14.4 \%$ of the PAR of incident $\mathrm{AF}$ alone, and a staggering $27 \%$ of the risk of developing AF with HF. In light of the ongoing obesity epidemic worldwide, reducing obesity may thus have the greatest impact in reducing the combination of $\mathrm{AF}$ and $\mathrm{HF}$, and randomised trials are needed to test this hypothesis. Systolic blood pressure $>140 \mathrm{~mm} \mathrm{Hg}$ also contributed to a large proportion of the PAR in this analysis, accounting for $17.0 \%$ to $27.5 \%$ of incident $\mathrm{AF}$ with $\mathrm{HF}$, and consistent with results observed in the Women's Health Study. ${ }^{22}$ A recent analysis of the SPRINT trial found that 
Table 5 Estimated population attributable fractions $(95 \% \mathrm{Cl})$, for modifiable risk factors by heart failure status

\begin{tabular}{lllll}
\hline & \multicolumn{2}{l}{ Atrial fibrillation without heart failure } & \multicolumn{2}{l}{ Atrial fibrillation with heart failure } \\
\hline & MPP & MDCS & \multicolumn{1}{l}{ MPP } & MDCS \\
\hline Full cohort & & & & \\
BMI $\geq 25$ & $10.4(7.8-12.9)$ & $13.6(10.0-17.2)$ & $26.9(22.9-30.6)$ & $26.3(19.7-32.4)$ \\
\hline Current smoking & $6.7(4.2-9.2)$ & $1.2(-0.7-3.0)$ & $19.3(15.8-22.8)$ & $10.3(7.7-12.9)$ \\
\hline SBP $\geq 140$ & $4.6(2.9-6.3)$ & $14.6(10.6-18.6)$ & $16.7(14.1-19.2)$ & $26.9(19.1-34.0)$ \\
\hline Prevalent diabetes at baseline & $-0.09(-0.6-0.5)$ & $-0.1(-0.9-0.7)$ & $2.0(1.1-2.9)$ & $5.3(4.2-6.3)$ \\
\hline Total modifiable PAF & $20.1(16.6-23.6)$ & $27.0(22.2-31.4)$ & $51.8(48.0-55.3)$ & $54.1(47.7-59.8)$ \\
\hline Men & & & & \\
\hline BMI $\geq 25$ & $9.2(6.0-12.3)$ & $11.9(5.8-17.6)$ & $27.5(22.8-31.8)$ & $24.7(14.4-33.8)$ \\
\hline Current smoking & $7.0(3.7-10.1)$ & $0.1(-2.7-2.8)$ & $19.7(15.3-23.8)$ & $14.1(10.7-17.4)$ \\
\hline SBP $\geq 140$ & $4.7(2.7-6.6)$ & $15.3(9.5-20.7)$ & $16.2(13.1-19.1)$ & $31.8(21.7-40.7)$ \\
\hline Prevalent diabetes at baseline & $-0.02(-0.8-0.5)$ & $-0.2(-1.4-1.0)$ & $2.5(1.6-3.4)$ & $4.7(3.0-6.4)$ \\
\hline Total modifiable PAF & $19.3(14.9-23.5)$ & $25.2(17.7-32.0)$ & $52.1(47.6-56.3)$ & $57.8(49.2-64.9)$ \\
\hline Women & & & & \\
BMI>25 & $12.5(8.2-16.7)$ & $14.3(9.9-18.5)$ & $26.4(19.1-33.0)$ & $27.1(18.5-34.8)$ \\
\hline Current smoking & $6.4(2.5-10.1)$ & $2.1(-0.3-4.6)$ & $18.1(12.3-23.5)$ & $5.0(0.6-9.2)$ \\
\hline SBP $\geq 140$ & $4.5(1.0-7.8)$ & $13.2(7.5-18.6)$ & $18.5(13.3-23.3)$ & $19.2(6.0-30.5)$ \\
\hline Prevalent diabetes at baseline & $-0.02(-1.3-1.2)$ & $0.0(-1.0-0.9)$ & $0.3(-2.4-2.8)$ & $6.0(4.7-7.3)$ \\
\hline Total modifiable PAF & $21.8(15.7-27.5)$ & $27.1(20.8-32.9)$ & $51.6(44.2-58.0)$ & $47.2(36.2-56.3)$ \\
\hline
\end{tabular}

All PAFs estimated in a model adjusted for age, sex (where applicable), height, hypertension (SBP $\geq 140 \mathrm{mmHg}$ ), overweight (BMI $\geq 25 \mathrm{~kg} /$ $\mathrm{m}^{2}$ ), current smoking, prevalent diabetes and history of coronary events. Total PAF differs from the sum of PAFs due to overlap between risk factors.

BMI, body mass index; MDCS, Malmö Diet and Cancer Study; MPP, Malmö Preventive Project; PAF, population attributable fraction; SBP, systolic blood pressure.

intensive blood pressure control $(<120 \mathrm{~mm} \mathrm{Hg})$ was associated with a decreased risk of acutely decompensated $\mathrm{HF}^{25}$ not only highlighting the importance of systolic blood pressure control and its relationship with HF, but also suggesting that lower blood pressure targets may achieve an even greater impact. Prevalent coronary artery disease was associated with preferential development of $\mathrm{AF}$ with HF compared with AF alone in MDCS, but not in the MPP cohort. The latter finding was likely due to the younger baseline age and low prevalence of participants with preexisting coronary disease at baseline in MPP $(0.4 \%)$.

Our study must be interpreted in light of several limitations. First, the study cohorts were composed primarily of individuals of European descent, and the results may not be entirely generalisable to individuals of other ethnicities or race. Second, patient characteristics were only available at baseline and thus we were unable to perform time-updated analyses to confirm the observed associations. However, our findings were consistent with prior reports, ${ }^{22}$ and the associations remained robust even after sensitivity analysis. Third, clinical endpoint data such as the occurrence of incident $\mathrm{AF}$ or $\mathrm{HF}$ were obtained from Swedish administrative registries, potentially leading to misclassification bias. However, clinical endpoints in the MPP and MDCS cohorts have been recently shown to be highly accurate $(>95 \%) .{ }^{11}$ Any misclassification that may have occurred was likely non-differential, and would have biassed our results towards the null. Finally, the occurrence of clinical endpoints was determined in the hospital setting, therefore any AF or HF cases that did not lead to hospitalisation would not have been detected. However, this would have also biassed our results towards the null.

In summary, in this analysis of two large, prospective, population-based cohorts free of $\mathrm{AF}$ and $\mathrm{HF}$ at baseline, BMI $>25 \mathrm{~kg} / \mathrm{m}^{2}$, systolic blood pressure $>140 \mathrm{~mm} \mathrm{Hg}$ and active cigarette smoking were more strongly associated with the development of the combination of $\mathrm{AF}$ and $\mathrm{HF}$, than $\mathrm{AF}$ alone. These modifiable risk factors accounted for greater than $50 \%$ of the PAR. Randomised trials are needed to assess whether modification of these three risk factors can reduce the incidence of $\mathrm{AF}$ with $\mathrm{HF}$ and subsequently decrease mortality.

\section{Twitter Linda S B Johnson @ljsMD}

Contributors Dr JW is the first and corresponding author. He was involved in study design and conception, data analysis and interpretation, drafting and revising of the manuscript and final approval. He is the guarantor. Dr LJ is the senior author and was involved in study design and conception, data analysis and interpretation, manuscript revision and final approval. Drs DC and Healey were involved in study design, data interpretation, manuscript revision and final approval.

Funding Dr LJ is supported by governmental grants within the Swedish National Health Services, the Swedish Heart and Lung Association, the Swedish Society of Medicine and by the Swedish Heart and Lung Foundation. Dr DC holds a McMaster University Department of Medicine Mid-Career Research Award. His work is 
supported by the Hamilton Health Sciences RFA Strategic Initiative Program. Dr JH is the Population Health Research Institute Chair in Cardiovascular Research.

Competing interests None declared.

Patient consent for publication Not required.

Ethics approval The study conforms to the declaration of Helsinki and the regional Ethics Review Board in Lund approved the study.

Provenance and peer review Not commissioned; externally peer reviewed.

Data availability statement Data are available upon reasonable request. Please contact Drs JA Wong or $\mathrm{L}$ Johnson for details.

Open access This is an open access article distributed in accordance with the Creative Commons Attribution Non Commercial (CC BY-NC 4.0) license, which permits others to distribute, remix, adapt, build upon this work non-commercially, and license their derivative works on different terms, provided the original work is properly cited, appropriate credit is given, any changes made indicated, and the use is non-commercial. See: http://creativecommons.org/licenses/by-nc/4.0/.

ORCID iD

Jorge A Wong http://orcid.org/0000-0002-2527-8936

\section{REFERENCES}

1 Braunwald E. Shattuck lecture--cardiovascular medicine at the turn of the millennium: triumphs, concerns, and opportunities. $N$ Engl J Med 1997;337:1360-9.

2 Benjamin EJ, Virani SS, Callaway CW, et al. Heart disease and stroke Statistics-2018 update: a report from the American heart association. Circulation 2018;137:e67-492.

3 Lloyd-Jones DM, Larson MG, Leip EP, et al. Lifetime risk for developing congestive heart failure: the Framingham heart study. Circulation 2002;106:3068-72.

4 Benjamin EJ, Wolf PA, D'Agostino RB, et al. Impact of atrial fibrillation on the risk of death: the Framingham heart study. Circulation 1998;98:946-52.

5 Kotecha D, Lam CSP, Van Veldhuisen DJ, et al. Heart Failure With Preserved Ejection Fraction and Atrial Fibrillation: Vicious Twins. J Am Coll Cardiol 2016;68:2217-28.

6 Santhanakrishnan R, Wang N, Larson MG, et al. Atrial fibrillation begets heart failure and vice versa: temporal associations and differences in preserved versus reduced ejection fraction. Circulation 2016;133:484-92.

7 Conen D, Chae CU, Glynn RJ, et al. Risk of death and cardiovascular events in initially healthy women with new-onset atrial fibrillation. JAMA 2011;305:2080-7.

8 Sartipy U, Dahlström U, Fu M, et al. Atrial fibrillation in heart failure with preserved, Mid-Range, and reduced ejection fraction. JACC Heart Fail 2017;5:565-74.
9 Rienstra M, Damman K, Mulder BA, et al. Beta-Blockers and outcome in heart failure and atrial fibrillation: a meta-analysis. JACC Heart Fail 2013;1:21-8.

10 Nilsson PM, Nilsson J-A, Berglund G. Population-attributable risk of coronary heart disease risk factors during long-term follow-up: the Malmö preventive project. J Intern Med 2006;260:134-41.

11 Smith JG, Platonov PG, Hedblad B, et al. Atrial fibrillation in the Malmö diet and cancer study: a study of occurrence, risk factors and diagnostic validity. Eur J Epidemiol 2010;25:95-102.

12 Li C, Aronsson CA, Hedblad B, et al. Ability of physical activity measurements to assess health-related risks. Eur J Clin Nutr 2009;63:1448-51.

13 Kristenson $\mathrm{H}$, Trell E. Indicators of alcohol consumption: comparisons between a questionnaire (Mm-MAST), interviews and serum gamma-glutamyl transferase (GGT) in a health survey of middle-aged males. Br J Addict 1982;77:297-304.

14 Ludvigsson JF, Andersson E, Ekbom A, et al. External review and validation of the Swedish national inpatient register. BMC Public Health 2011;11:450

15 Ingelsson E, Arnlöv J, Sundström J, et al. The validity of a diagnosis of heart failure in a hospital discharge register. Eur $J$ Heart Fail 2005;7:787-91.

16 Lunn M, McNeil D. Applying COX regression to competing risks. Biometrics 1995;51:524-32.

17 Conen D, Glynn RJ, Sandhu RK, et al. Risk factors for incident atrial fibrillation with and without left atrial enlargement in women. Int $J$ Cardiol 2013;168:1894-9.

18 Newson RB. Attributable and Unattributable risks and fractions and other scenario comparisons. Stata J 2013;13:672-98.

19 Pandey A, Kim S, Moore C, et al. Predictors and Prognostic Implications of Incident Heart Failure in Patients With Prevalent Atria Fibrillation. JACC Heart Fail 2017;5:44-52.

20 Potpara TS, Polovina MM, Licina MM, et al. Predictors and prognostic implications of incident heart failure following the first diagnosis of atrial fibrillation in patients with structurally normal hearts: the Belgrade atrial fibrillation study. Eur J Heart Fail 2013;15:415-24.

21 Schnabel RB, Rienstra M, Sullivan LM, et al. Risk assessment for incident heart failure in individuals with atrial fibrillation. Eur $J$ Heart Fail 2013;15:843-9.

22 Chatterjee NA, Chae CU, Kim E, et al. Modifiable Risk Factors for Incident Heart Failure in Atrial Fibrillation. JACC Heart Fail 2017;5:552-60.

23 Tedrow UB, Conen D, Ridker PM, et al. The long- and short-term impact of elevated body mass index on the risk of new atrial fibrillation the WHS (women's health study). J Am Coll Cardiol 2010;55:2319-27.

24 Kenchaiah S, Evans JC, Levy D, et al. Obesity and the risk of heart failure. N Engl J Med 2002;347:305-13.

25 Upadhya B, Rocco M, Lewis CE, et al. Effect of intensive blood pressure treatment on heart failure events in the systolic blood pressure reduction intervention trial. Circ Heart Fail 2017; 10:e003613. 